\title{
Rhythm-Speech Correlations in a Corpus of Senegalese Drum Language
}

\author{
Sofiya Ros* \\ Utrecht Institute of Linguistics OTS, Utrecht University, Utrecht, Netherlands
}

In some African cultures, drumming is used for expressing linguistic meanings. Our research focuses on Senegalese musical traditions of encoding linguistic messages on the sabar drums. Senegalese drummers have the practice of playing drums in correlation to speech. We consider rhythms and their linguistic correlates as being part of a Sabar drum language. The long-term goal of this investigation is to establish the linguistic properties of the Sabar drum language. To this end, this work relies on two kinds of research materials collected from Senegalese drummers: bàkks (classical sabar phrases, not improvised on the spot) and sabar improvisations including their translation to Wolof. We study the regularities between Wolof units and sabar rhythms in the collected data. We tested the hypothesis of a syllable-level correspondence between Sabar and Wolof, assuming that each sabar stroke represents a syllable or a

OPEN ACCESS

Edited by:

Laura McPherson,

Dartmouth College, United States

Reviewed by:

Harry Van Der Hulst,

University of Connecticut,

United States

Ka Omar,

University of Maryland, Baltimore

County, United States

*Correspondence:

Sofiya Ros

s.ros@uu.n

Specialty section: This article was submitted to

Language Sciences,

a section of the journal

Frontiers in Communication

Received: 18 December 2020

Accepted: 21 June 2021

Published: 01 July 2021

Citation:

Ros S (2021) Rhythm-Speech Correlations in a Corpus of Senegalese

Drum Language.

Front. Commun. 6:643683.

doi: 10.3389/fcomm.2021.643683 number of syllables in Wolof, where the nature of the correspondence depends on the phonetic or phonological properties of a vowel in a syllable. The analysis has shown that different drum strokes are more commonly associated with different types of vowels (front, central or back; open, mid-open/mid-closed or closed vowels).

Keywords: drum language, Wolof, Senegal, music, phonology, drums, sabar

\section{INTRODUCTION}

Speech surrogates using drums are present in Africa, South America, Asia and Oceania (Stern, 1957; Sebeok and Umiker-Sebeok, 1976). These are emulated speech systems, which are obtained by transforming spoken language into drum sounds (Seifart et al., 2018). Most languages of the Niger-Congo family, present in Africa, are tonal, meaning that differences in relative pitch trigger differences in lexical meaning and syntactic functions. Drummed speech has been described almost exclusively for tonal languages. For example, the Yoruba people of Nigeria play drums to mimic the spoken Yoruba language (Euba 1990; Villepastour, 2010) and in Ghana drumming was widely used among the Akan people to imitate the spoken Akan language (Nketia, 1963).

Our research focuses on Senegalese traditions of encoding linguistic messages on drums. Senegalese drummers follow the practice of playing drums in correlation to speech. These drummers belong to the social class of griots (Hale, 1998, Tang, 2007), and their most common drum is a single-headed drum known as sabar. In Senegal, sabar drumming appears in different sorts of events such as sport events, life-cycle ceremonies, political gatherings. Although nowadays the sabar drums are rarely used as a speech surrogate and their main function is to entertain the listener rather than to convey a linguistic message, the practice of playing the sabar still maintains a close connection to linguistic expressions (Winter, 2014). The formal correspondence of sabar rhythms with spoken language is different from other documented African drum languages. Unlike most other languages of 
TABLE 1 | Sabar phonemes.

\begin{tabular}{|c|c|c|}
\hline Code & Variants & Description \\
\hline \multicolumn{3}{|c|}{ Hand strokes } \\
\hline Gin & Gi, bin & Bass sound; the hand strikes the edge or the middle of the skin \\
\hline Pin & & The hand strikes the edge of the drum \\
\hline Pax & $\mathrm{Pa}$, ba, bax, mbar, mbax & The full palm strikes the whole skin \\
\hline \multicolumn{3}{|c|}{ Stick strokes } \\
\hline $\tan$ & Ta, sa, san, dan, ja & The stick strikes the centre of the drum and bounces off \\
\hline tac & Tas, tach & The stick strikes the centre of the drum and bounces off, while the hand damps the edge of the drum \\
\hline $\mathrm{ce}$ & $\tilde{\mathrm{Na}}$, ca, cek, cex, te & The stick strikes the drum and is left there \\
\hline \multicolumn{3}{|c|}{ Hand + stick strokes } \\
\hline rwan & Rwa & pin tan or pax tan \\
\hline rwe & Rwex & Pax ce \\
\hline drin & & Tan gin \\
\hline
\end{tabular}

the Niger-Congo family, Wolof is not a tonal language and sabar rhythms do not mimic the pitch of word sounds.

We focus on linguistically meaningful sabar rhythms. This class of rhythms and their linguistic correlates is referred to here as Sabar. To examine possible regularities between Wolof and sabar rhythms, we carry out a case study on our collected dataset. Two general hypotheses are examined. According to the word-level hypothesis, each stroke in Sabar represents a class of words in Wolof that share some specific sound properties. According to the syllable-level hypothesis, each stroke in Sabar represents a class of syllables in Wolof that share some specific sound properties. Each of the hypotheses will be described in further detail below.

\section{MATERIALS AND METHODS}

\section{Basic Phonemic Units}

Playing sabar involves at least nine different drum strokes, which can be seen as the basic units of the genre. These strokes appear in longer sabar rhythmic phrases which can be correlated with spoken utterances in Wolof. Sabar sounds are produced by one hand and one stick. Both the stick and the hand are used for beating rhythms and for damping the sound (Winter, 2014). Sabar basic units, which we call Sabar phonemes, are produced by different combinations of applying the hand and the stick onto certain parts of the sabar head. Each sabar phoneme has a special oral correlate.

As documented in (Winter, 2014) Sabar phonemes can be divided into the following three classes:

- Hand strokes: produced by one hand, which may bounce or stop on the skin.

- Stick strokes: produced by the stick, where the hand may be used for damping the sound.

- Hand + stick strokes: sequences of hand strokes and stick strokes; these sequences are perceived as minimal rhythmic units.

Each of the Sabar phonemes has an oral code that griots use when referring to rhythms. The main Sabar phonemes and their oral codes are given in Table 1. The table is taken from (Winter, 2014) and with a few more variants for the oral codes (in italic).

The code for any given phoneme refers to the way the sound is perceived, not to the precise technique of its production, which may vary between different types of sabar drums (Tang, 2007). The codes can be called slightly differently, depending on personal choice of a drummer, speed of playing or the drum that is being used.

\section{Materials}

This work relies on research materials collected during previous expeditions to Senegal. Materials include improvised material as well as traditional bakks. These are traditional texts or phrases in Sabar, known to many griots and learnt by heart. Recordings start with the phrase in Wolof, which is followed by the corresponding rhythm. For each recording there is a transcription of both the text and the rhythm. To transcribe the rhythm, the sabar stroke coding system is used, without any detailed annotation of temporal relations between strokes or their acoustic properties.

402 recordings were made. Of them, six recordings were excluded due to the fact that the transcription of the sabar rhythm was missing. Of the remaining 396 pieces, 35 are bàkks and 361 are improvised texts. The average number of words and syllables per piece in the spoken language is 11 and 15, respectively. The average number of strokes per piece is 15 . To gain more insight into sabar practices, fifty of the Wolof pieces were translated into English by a Wolof speaker.

The recordings were made in live sessions with the drummers. The work was conducted in the years 2018-2019 in Campement Nguekhohk, Senegal ${ }^{1}$. All recordings were made with griots of the same family, where 2-3 drummers were present in each session. The drummers were asked to come up with a traditional bakk or improvisation in Wolof, play the corresponding rhythm and utter the rhythm's oral codes.
${ }^{1}$ The data were collected by C.L.A. Bourdeau in the years 2018-2019 as part of the NWO-project no. 360-89-060 
TABLE 2 | Frequencies of strokes.

\begin{tabular}{lcc}
\hline Stroke & Frequency & $\begin{array}{c}\text { Percentage } \\
\text { (\% of 5,454) }\end{array}$ \\
\hline Gin & 1966 & 36 \\
Tan & 1814 & 33.3 \\
Rwan & 689 & 12.6 \\
Pax & 428 & 7.8 \\
Tac & 317 & 5.8 \\
Ce & 182 & 3.3 \\
Drin & 32 & 0.6 \\
Rwe & 26 & 0.5 \\
\hline
\end{tabular}

TABLE 3 | The most common word-stroke combinations.

\begin{tabular}{lllc}
\hline Wolof word & Sabar stroke(s) & English translation & Count \\
\hline $\mathrm{La}$ & Tan & You & 66 \\
$\mathrm{Ci}$ & Gin & At/in & 63 \\
$\mathrm{Bu}$ & Gin & Which & 51 \\
$\mathrm{Ko}$ & Tan & Her/him/it & 47 \\
$\mathrm{Li}$ & Gin & The & 47
\end{tabular}

Example 1) illustrates an improvised text. The text in Wolof is followed by the codes of the corresponding drum strokes:

\begin{tabular}{|c|c|c|c|c|}
\hline $\begin{array}{l}\text { xol } \\
\text { rwan }\end{array}$ & $\begin{array}{l}\text { bu } \\
\text { gin }\end{array}$ & $\begin{array}{l}\text { baax } \\
\text { tan }\end{array}$ & & \\
\hline & gën & xol & bu & bon \\
\hline rwan & $\tan$ & $\tan$ & $\tan$ & gin \\
\hline
\end{tabular}

(A beautiful heart

Is way better than an ugly heart)

\section{Methods of Analysis}

In order to examine possible regularities between Wolof units and sabar strokes in the collected dataset, two hypotheses were studied. According to the word-level hypothesis, each word in Wolof has a specific stroke or stroke sequence associated to it. According to the syllable-level hypothesis, each syllable in Wolof has a specific stroke or stroke sequence associated to it, where the nature of the correspondence depends on the phonetic or phonological properties of the vowel in a syllable.

For the word-level analysis all the texts were divided into pairs, the first element of each being the Wolof word and the second element being the corresponding stroke or combination of strokes. This resulted in 4,290 pairs.

To test the syllable-level hypothesis, Wolof words were syllabified (Ka, 1988). The texts were divided into pairs: a Wolof syllable and the corresponding stroke. In most of the cases the number of strokes and syllables per line was the same. Out of 5705 I excluded pairs where there was no correlation between the number of strokes and syllables (for example, a one-syllable word in Wolof that has two strokes correlated to it; or a longer word in Wolof that has one correlating stroke). In total there were 251 such cases, less than $5 \%$ of pairs in the dataset. This resulted in 5,454 pairs of syllables and strokes.
TABLE 4 | Example of restructured data.

\begin{tabular}{lllll}
\hline Sabar & Wolof & Wolof_pos & Wolof_len & Wolof_open \\
\hline Gin & a & Central & Short & Open \\
Drin & bes & Front & Short & Mid-open \\
Pax & Daan & Central & Long & Open \\
Tan & Dem & Front & Short & Mid-open \\
\hline
\end{tabular}

In Table 2 the frequencies of eight different strokes in the data are presented. The stroke pin was not present throughout the whole data.

\section{Word-Level Hypothesis}

According to the word-level hypothesis each Wolof word is associated to a specific sabar stroke or combination of strokes. In Table 3 the five most common word-stroke combinations in the dataset are presented. The fourth column shows the number of occurrences of each combination.

As seen in the table, the most common combinations involve one-syllable words. Therefore, for now we focused on the syllablehypothesis, since testing the word-level hypothesis is not straightforward using the data available to us at the moment.

\section{Syllable-Level Hypothesis}

According to the syllable-level hypothesis, syllables in Wolof have specific drum strokes associated to them, where the nature of the correspondence depends on the phonetic or phonological properties of the vowel in a syllable: length, openness and front/central/back property of a vowel.

As documented in (Ward, 1939: 322, Nikiforova 1981: 15, Unseth 2009: 1, Ka 1993: 7), vowel-length is a significant element of Wolof (for instance, xol 'heart' vs. xool 'to look at'). Therefore, all the syllables were divided into two groups: syllables with short and long vowels. From the total of 5,454 analysed Wolof syllables, 4,375 (80\%) contained short vowels and 1,079 (20\%)long vowels. The syllables were further divided into three groups based on the front/central/back property of the vowel. Wolof front vowels are [i], [e]; central — [a] [ə] (spelled “ë" here); back — [o] [u] [o] (Ward, 1939: 321, Nikiforova, 1981: 15, Ka 1993: $4)$. From the total of 5,454 analysed Wolof syllables, 2,445 (45\%) contained central vowels, 1,660 (30\%) - front vowels, 1,349 (25\%) - back vowels. Further, syllables were divided into three groups based on their openness: open, middle (midopen/mid-closed), closed. Wolof open vowels are [a], middle - [e] [ə] [o], closed - [i] [u] (Ward, 1939: 321, Nikiforova, 1981: 15). From the total of 5,454 analysed Wolof syllables, $2,160(40 \%)$ contained open vowels, $1835(34 \%)$ - closed vowels, $1,459(27 \%)$ - middle (mid-open/mid-closed) vowels.

In the paper the orthographic symbols suggested by the drummers are used. The orthographic symbols used in the paper are presented in the Figure $\mathbf{1}$.

In order to test the syllable-level hypothesis, the data was presented in a table where in each row there was a specific stroke, an associated syllable and the properties of a vowel in this stroke: length (short/long), position (front/central/back) and openness (open/middle/closed). Table 4 is an example, where Wolof_pos 


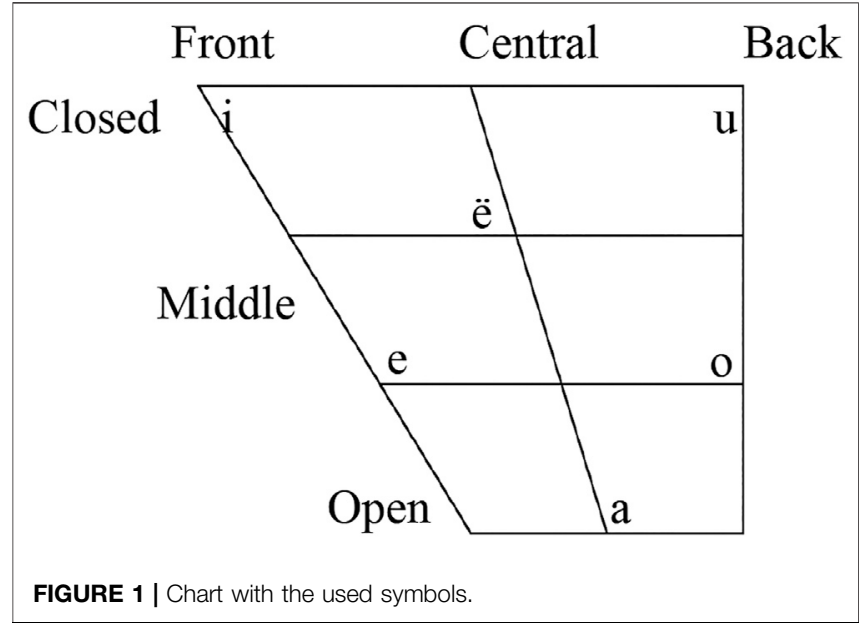

TABLE 5 | Cross-tabulation of stroke types and vowel lengths.

\begin{tabular}{lcc} 
& \multicolumn{2}{c}{ Vowel length } \\
\cline { 2 - 3 } Stroke & Short & Long \\
\hline Ce & 148 & 34 \\
& $(0.4)$ & $(-0.4)$ \\
Drin & 20 & 12 \\
& $(-2.5)$ & $(2.5)$ \\
Gin & $\mathbf{1 7 3 1}$ & $\mathbf{2 3 5}$ \\
& $\mathbf{( 1 0 . 9 )}$ & $\mathbf{( - 1 0 . 9 )}$ \\
Pax & 355 & 73 \\
& $(1.5)$ & $(-1.5)$ \\
Rwan & $\mathbf{4 5 1}$ & $\mathbf{2 3 8}$ \\
& $\mathbf{( - 1 0 . 4 )}$ & $\mathbf{( 1 0 . 4 )}$ \\
Rwe & 21 & 5 \\
& $(0.1)$ & $(-0.1)$ \\
Tac & $\mathbf{2 3 2}$ & $\mathbf{8 5}$ \\
& $\mathbf{( - 3 . 2 )}$ & $\mathbf{( 3 . 2 )}$ \\
Tan & 1,417 & 397 \\
& $(-2.8)$ & $(2.8)$ \\
\hline
\end{tabular}

Absolute adjusted standardised residuals greater than three are highlighted in bold.

stands for the front/central/back property of the vowel in the Wolof syllable associated with the given stroke, Wolof_len-for the length and Wolof_open-for the openness of the syllable. This data was analysed using SPSS software.

\section{RESULTS}

\section{Length}

A chi-square test of independence was conducted between the stroke type and the length of the vowel in the corresponding syllable. All expected cell frequencies were greater than five. There was a statistically significant association between the stroke type and the length of the vowel in the corresponding syllable, $\chi 2(7)=193.94$, $p<0.0005$. The association was weak, Cramer's $V=0.189$ (Cohen 1988).

A cross-tabulation of stroke types and vowel lengths is presented in Table 5. Adjusted residuals appear in parentheses below the observed frequencies. A residual is the difference
TABLE 6 | Cross-tabulation of stroke types and vowel positions.

\begin{tabular}{lccc}
\hline Stroke & \multicolumn{3}{c}{ Vowel position } \\
\cline { 2 - 4 } & Front & Central & Back \\
\hline Ce & $\mathbf{8 1}$ & 81 & $\mathbf{2 0}$ \\
& $\mathbf{( 4 . 2 )}$ & $(-0.1)$ & $\mathbf{( - 4 . 4 )}$ \\
Drin & 8 & 17 & 7 \\
& $(-0.7)$ & $(0.9)$ & $(-0.4)$ \\
Gin & $\mathbf{8 3 7}$ & $\mathbf{3 6 2}$ & $\mathbf{7 6 7}$ \\
& $\mathbf{( 1 4 . 6 )}$ & $\mathbf{( - 2 9 . 5 )}$ & $\mathbf{( 1 8 . 3 )}$ \\
Pax & $\mathbf{6 1}$ & $\mathbf{3 0 0}$ & $\mathbf{6 7}$ \\
& $\mathbf{( - 7 . 6 )}$ & $\mathbf{( 1 0 . 9 )}$ & $\mathbf{( - 4 . 5 )}$ \\
Rwan & $\mathbf{1 1 3}$ & $\mathbf{3 9 7}$ & 179 \\
& $\mathbf{( - 8 . 6 )}$ & $\mathbf{( 7 . 2 )}$ & $(0.8)$ \\
Rwe & $\mathbf{2 1}$ & 4 & 1 \\
& $\mathbf{( 5 . 6 )}$ & $(-3.0)$ & $(-2.5)$ \\
Tac & $\mathbf{1 9 7}$ & $\mathbf{9 5}$ & $\mathbf{2 5}$ \\
& $\mathbf{( 1 2 . 6 )}$ & $\mathbf{( - 5 . 5 )}$ & $\mathbf{( - 7 . 2 )}$ \\
Tan & $\mathbf{3 4 2}$ & $\mathbf{1 , 1 8 9}$ & $\mathbf{2 8 3}$ \\
& $\mathbf{( - 1 3 . 1 )}$ & $\mathbf{( 2 1 . 7 )}$ & $\mathbf{( - 1 1 . 0 )}$
\end{tabular}

Absolute adjusted standardised residuals greater than three are highlighted in bold.

between the expected frequency and the observed frequency. The residuals are standardized so that they have an approximately standard normal distribution with the approximation improving at larger sample sizes. The adjusted standardized residual higher than 3 mark the cells that deviate significantly from independence (Agresti, 2007). Absolute adjusted standardised residuals greater than three are highlighted in bold.

\section{Position}

A chi-square test of independence was conducted between the stroke type and the front/central/back property of the vowel in the corresponding syllable. All expected cell frequencies were greater than five. There was a statistically significant association between the stroke type and the position of the vowel in the corresponding syllable, $\chi 2(14)=1,274.9, p<0.0005$. The association was moderately strong, Cramer's $V=0.342$.

A cross-tabulation of stroke types and vowel positions is presented in Table 6. Adjusted residuals appear in parentheses below the observed frequencies. Absolute adjusted standardised residuals greater than three are highlighted in bold.

\section{Openness}

A chi-square test of independence was conducted the between stroke type and the openness of the vowel in the corresponding syllable. All expected cell frequencies were greater than five. There was a statistically significant association between the stroke type and the openness of the vowel in the corresponding syllable, $\chi 2(14)=2,476$, $p<0.0005$. The association was very strong, Cramer's $V=0.476$.

A cross-tabulation of stroke types and vowel openness positions is presented in Table 7. Adjusted residuals appear in parentheses below the observed frequencies. Absolute adjusted standardised residuals greater than three are highlighted in bold.

The statistical analysis therefore shows that some regularities between sabar strokes and Wolof syllables exist, namely the following (only the results with absolute adjusted standardized residuals greater than three are presented): 
TABLE 7 | Cross-tabulation of stroke types and vowel openness.

\begin{tabular}{lccc}
\hline Stroke & \multicolumn{3}{c}{ Vowel position } \\
\cline { 2 - 4 } & Open & Mid-open/mid-closed & Close \\
\hline \multirow{2}{*}{ Ce } & 71 & $\mathbf{8 1}$ & $\mathbf{3 0}$ \\
& $(-0.2)$ & $\mathbf{( 5 . 5 )}$ & $\mathbf{( - 5 . 0 )}$ \\
Drin & 9 & 15 & 8 \\
& $(-1.3)$ & $(2.6)$ & $(-1.0)$ \\
Gin & $\mathbf{2 4 4}$ & $\mathbf{2 9 5}$ & $\mathbf{1 , 4 2 7}$ \\
& $\mathbf{( - 3 0 . 8 )}$ & $\mathbf{( - 1 4 . 7 )}$ & $\mathbf{( 4 5 . 7 )}$ \\
Pax & $\mathbf{2 8 5}$ & $\mathbf{8 4}$ & $\mathbf{5 9}$ \\
& $\mathbf{( 1 1 . 9 )}$ & $\mathbf{( - 3 . 5 )}$ & $\mathbf{( - 9 . 1 )}$ \\
Rwan & $\mathbf{3 7 1}$ & $\mathbf{2 5 7}$ & $\mathbf{6 1}$ \\
& $\mathbf{( 8 . 2 )}$ & $\mathbf{( 6 . 7 )}$ & $\mathbf{( - 3 . 2 )}$ \\
Rwe & 3 & $\mathbf{2 2}$ & $\mathbf{1}$ \\
& $(-2.9)$ & $\mathbf{( 6 . 7 )}$ & $\mathbf{( - 3 . 2 )}$ \\
tac & 74 & $\mathbf{2 0 6}$ & $\mathbf{3 7}$ \\
& $(-6.1)$ & $\mathbf{( 1 5 . 8 )}$ & $\mathbf{( - 8 . 5 )}$ \\
Tan & $\mathbf{1 , 1 0 3}$ & 499 & $\mathbf{2 1 2}$ \\
& $\mathbf{( 2 2 . 6 )}$ & $(0.9)$ & $\mathbf{( - 2 4 . 2 )}$ \\
& & &
\end{tabular}

Absolute adjusted standardised residuals greater than three are highlighted in bold.

Strokes' preferences for vowel length (weak association):

gin-short

rwan-long

Strokes' preferences for vowel position (moderate association):

$$
\begin{aligned}
& \text { ce-front } \\
& \text { gin-back (and front) } \\
& \text { pax-central } \mathrm{r} \\
& \text { wan-central } \\
& \text { tac-front } \\
& \text { tan-central }
\end{aligned}
$$

Strokes' preferences for vowel openness (strong association):

$$
\begin{aligned}
& \text { ce-mid-open/mid-closed } \\
& \text { gin-closed } \\
& \text { pax-open } \\
& \text { rwan-open } \\
& \text { rwe-mid-open/mid-closed } \\
& \text { tac-mid-open/mid-closed } \\
& \text { tan-open }
\end{aligned}
$$

The association was weak for the strokes' preferences for vowel length, moderately strong for vowel position and very strong for vowel openness, therefore we suggest to take into account only the results for the vowel position and openness for now. These results suggest there is a Wolof-Sabar correspondence that depends on the phonetic and phonological properties of a vowel in a syllable.

\section{DISCUSSION}

This paper reports the first study that is meant to uncover statistical regularities between between units in the spoken language and strokes in the drum language. We used a dataset of sabar rhythms and their corresponding Wolof phrases. Two different hypotheses-the wordlevel hypothesis and the syllable-level hypothesis-were examined. While the data did not allow a detailed study of the word-level hypothesis, descriptive and inferential statistics were used in order to test the syllable-level hypothesis. Evidence for this hypothesis was found: the vowel position and the vowel openness affect the preference of an associated stroke with moderate and strong strength of association respectively. Such parameters as vowels openness and the front/back distinctions are the most salient and basic parameters for representing vowel systems and for this reason they are reflected in the Sabar phonology. ${ }^{2}$

It has to be metioned that Wolof also has ATR vowel harmony, meaning that Wolof vowels harmonise based upon the phonological feature [ATR], or advanced tongue root, a widespread phonological pattern in African languages (Casali, 2008; Ka 1993; Unseth, 2009; Van der Hulst, 2018). In the current analysis we do not include this feature, however, it might also be reflected in the drum phonology.

Some of the limitations of this work should be pointed out in order to outline the room they leave for further research. First, the work is based on a limited number of pieces collected from one family of the drummers in Senegal. This has probably led to the fact that it did not allow for a detailed study of the word-level hypothesis. Second, the inherent difficulty of working with Sabar should also be mentioned. Unlike other drum languages, which are based on tonal languages and therefore imitate the pitch levels of the spoken language, Wolof and the Sabar are not tonal, and working with them reguires different methods. This paper documents one attempt to develop such a method. Our study of the syllable-level hypothesis, while showing certain correlations, could not fully predict the relation between Wolof and Sabar. This suggests that there is much room for exploring further hypotheses about the relations between speech and rhythm in Sabar.

\section{DATA AVAILABILITY STATEMENT}

The raw data supporting the conclusion of this article will be made available by the authors, without undue reservation.

\section{ETHICS STATEMENT}

The present paper was ethically approved by the Ethics Assessment Committee of the Faculty of Humanities, FEtC reference number: 20-328-02.

\section{AUTHOR CONTRIBUTIONS}

The author confirms being the sole contributor of this work and has approved it for publication.

${ }^{2}$ With thanks to an anonymous reviewer for making this observation. 


\section{FUNDING}

This research was supported by NWO grant no. 360-89-060, project name "When language has a beat: Senegalese drum language and linguistic theory".

\section{REFERENCES}

Agresti, A. (2007). An Introduction to Categorical Data Analysis. 2nd ed. Hoboken, NJ: Wiley.

Casali, R. F. (2008). ATR Harmony in African Languages. Lang. Linguist. Compass 2 (3), 496-549.

Cohen, J. (1988). Statistical Power Analysis for the Behavioral Sciences. 2nd ed. New York: Psychology Press.

Euba, A. (1990). Yorùbá Drumming: The Dundun Tradition. Bayreuth: Bayreuth African Studies.

Hale, T. A. (1998). Griots and Griottes. Bloomington: Indiana University Press.

Ka, O. (1993). Wolof Phonology and Morphology. Lanham, MD: University Press of America.

Ka, O. (1988). "Wolof Syllable Structure: Evidence from a Secret Code," in Procedings of the Eastern States Conference on Linguistics 5th; Philadelphia, PA, September 30-October 1988. (Washington, DC: ERIC Clearinghouse).

Nikiforova, L. A. (1981). Yazyk Wolof [Wolof Language]. Moscow: Nauka.

Nketia, J. H. K. (1963). Drumming in Akan Communities of Ghana. Edinburgh: Published on behalf of the University of Ghana by T Nelson.

T. A. Sebeok and D. J. Umiker-Sebeok (Editor) (1976). Speech Surrogates: Drum and Whistle Systems. The Hague, Netherlands: Mouton.

Seifart, F., Meyer, J., Grawunder, S., and Dentel, L. (2018). Reducing Language to Rhythm: Amazonian Bora Drummed Language Exploits Speech Rhythm for Long-Distance Communication. 5.4, 170354. doi:10.1098/rsos.170354

\section{ACKNOWLEDGMENTS}

The author would like to thank Yoad Winter, Myrthe Hemker, Khady Postma, Corentin Bourdeau, Sophie Sabar, Art Mbaye, Ouzin Diop, Gana and Ndongo Diop and other members of Diop family in Senegal.

Stern, T. (1957). Drum and Whistle "Languages": An Analysis of Speech Surrogates. Am. Anthropologist 59, 487-506. doi:10.1525/aa.1957.59.3.02a00070

Tang, P. (2007). Masters of the Sabar: Wolof Griot Percussionists of Senegal. Philadelphia: Temple University Press.

Unseth, C. (2009). Vowel Harmony in Wolof. Australia, Occasional Papers in Applied Linguistics No. 7.

Van der Hulst, H. (2018). Asymmetries in Vowel Harmony: A Representational Account. Oxford, UK. Oxford University Press.

Villepastour, A. (2010). Ancient Text Messages of the Yorùbá Bàtá Drum: Cracking the Code. Surrey, UK. Ashgate.

Ward, I. C. (1939). A Short Phonetic Study of Wolof (Jolof): As Spoken in the Gamiba and in Senegal. Africa (3), 320-334. doi:10.2307/1155382

Winter, Y. (2014). On the Grammar of a Senegalese Drum Language. Language 90 (3), doi:10.1353/lan.2014.0061

Conflict of Interest: The author declares that the research was conducted in the absence of any commercial or financial relationships that could be construed as a potential conflict of interest.

Copyright (c) 2021 Ros. This is an open-access article distributed under the terms of the Creative Commons Attribution License (CC BY). The use, distribution or reproduction in other forums is permitted, provided the original author(s) and the copyright owner(s) are credited and that the original publication in this journal is cited, in accordance with accepted academic practice. No use, distribution or reproduction is permitted which does not comply with these terms. 